\title{
Autonomous Reconfigurable Control Allocation (ARCA) for Reusable Launch Vehicles*
}

\author{
A. S. Hodcl ${ }^{\dagger} \quad$ Ronnic Callahan ${ }^{\ddagger}$
}

Revision, January 7,2002

\section{Introduction}

The role of control allocation (CA) in modern acrospace vehicles is to compute a command vector $\delta_{c} \in \mathbb{R}^{n_{a}}$ that corresponding to commanded or desircd body-frame torques (moments) $\tau_{c}=\left[\begin{array}{lll}L & M & N\end{array}\right]^{T}$ to the vchicle, compensating for and/or responding to inaccuracics in off-linc nominal control allocation calculations, actuator failures and/or degradations (roduccd cffcctivncss), or actuator limitations (ratc/position saturation). The command vector $\delta_{c}$ may govern the bchavior of, c.g., acrosurfaces, reaction thrustcrs, cnginc gimbals and/or thrust vectoring. Typically, the individual moments gencrated in response to cach of the $n_{a}$ commands does not lic strictly in the roll, pitch, or yaw axcs, and so a common practicc is to group or gang actuators so that a onc-to-onc mapping from torque commands $\tau_{c}$ to actuator commands $\delta_{c}$ may be achicved in an off-line computed CA function.

We shall assume the existence of an off-line computed nominal lincar affine CA function

$$
\delta_{c}=F(x) \tau_{c}+\delta_{0}(x)
$$

where $\tau_{c}$ is the commanded torque vector, $x$ is a vchicle state vector, $\delta_{0}$ is a trim (ncutral torquc) vector and $F(x)$ is a matrix of nominal control allocation gains. Onc may intcrpret the columns of $F(x)$ as a set set of gains defining "ganged" actuators for cach control axis. The resulting nominal autopilot/control allocation block diagram is shown in Figure 1. The vector $\tau_{b}$ in Figure 1 refers to the body torques induced on the vehicle by the actuators. Idcally, the control allocation matrix $F(x)$ would be chosen to be the pseudo-inverse $G(x)^{\dagger}$ of the Jacobian matrix

$$
G(x)=\left.\left[\frac{\partial \tau_{b, i}}{\partial \delta_{j}}\right]\right|_{x} \in \mathbb{R}^{3 \times n_{a}}
$$

where $n_{a}$ is the number of actuators; that is, we wish to design the control allocation matrix $F(x)$

\footnotetext{
-This work was supported in part by NASA contract NAS8-01105 and in part by a NASA Graduate Student Research Fellowship.

†.s.hodel ceng. auburn.edu, Dept. Elect. \& Comp. Eng., 200 Broun Hall, Auburn C'niversity, Auburn, AL 36849-5201, corresponding author

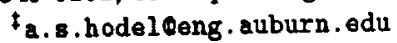




$\begin{array}{rcccccccc}\text { guidance } & \text { SMC } & \tau_{c} & & \delta_{c} & & \tau_{b} & \text { vchiclc } & \text { attutide } \\ \text { commands } & \text { autopilot } & & & & & & & \end{array}$

Figurc 1: Nominal autopilot/control allocation block diagram.

such that

$$
G(x) F(x)=\left[\begin{array}{lll}
1 & 0 & 0 \\
0 & 1 & 0 \\
0 & 0 & 1
\end{array}\right]
$$

so that the induced body-frame vehicle torques $\tau_{b}$ match the commanded body torques $\tau_{c}$. Howcver, duc to scnsor inaccuracy, modeling crrors, and data compression in the allocation function, the idcal condition (1.2) cannot be achicved. As such, scmidefinitc programming techniques [HSZ01], [BEFB94] arc used to design control allocation matrices $F(x)$ that achicve

$$
\|G(x) F(x)-I\|<1-\gamma(x)
$$

for some positive constant $\gamma$ to achicve the "best possible" allocation given off-line data.

The lincar affinc nominal control allocation law (1.1) by itsclf is inadequate for the control control allocation problem for four rcasons:

1. It fails to respond to torque allocation crrors that can be detected on-linc.

2. It fails to takc into account saturation issucs.

3. It fails to respond to on-line detcetcd failures in actuators, and

4. It fails to provide a framcwork to work with discretc-valucd (on-off) actuators such as reaction thrustcrs.

Dynamic control allocation [HC02] may be used to compensate for torque allocation crrors detected on-linc. DCA treats torque allocation crror as a unknown additive uncertainty in the system Jacobians

$$
G_{\text {lrue }}(x)=G(x)+\Delta_{G}(x)
$$

wherc $\Delta_{G}$ is an unknown gain that respects the condition

$$
\left\|G_{\text {lrue }}(x) F(x)-I\right\|<1
$$

over all opcrating conditions. If this condition is not met, then the CA problem is grcatly complicated, requiring the use of on-line system identification [CPM95] [CBP98], [CG86], [HJN91]. Discretc-valued actuators may be dcalt with by cither using pulso-width modulation to cmulate

Dept. Elect. \& Comp. Eng., Auburn Univ.

A. S. Hodcl \& R. Callahan 
continuous valued actuators or, where actuator structure will not permit the usc of PWM, onc may use thesc actuators as "back-up" to the continuous valucd actuators as in [HSZ01]. We address in this paper itcms 2 and 3 above by autonomous reconfigurable control allocation (ARCA).

An optimal solution of a constraincd control allocation problem involves the solution of convex programming problems [Buf97], [Dur93], [Enn98]. Somc hcuristic approximatc allocation solutions are presented in [BD95] such as computation of the attainable moment subset, gencralized inverses, and daisy chaining. Alternatively, adaptive control may be used in tandem with lincar systcm theory techniques in an attempt to avoid and/or compensate for actuator saturation [CGD ${ }^{+98}$ ]. In this paper we build on the work of [BD95], [Dur93], [BP98], [BD95], and [PB00] to present an online autonomous rcconfigurable control allocation technique that is computationally tractable and practical for usc in closcd loop with a robust autopilot (attitude control law) such as sliding mode control [SMJ ${ }^{+}$98], [BLM99], [SHJ00]. Our technique makes usc of a fast quadratic programming itcration stcp so that the actuator command $\delta_{c}$ results in a vehicle body torque $\tau_{b}$ that tracks the commanded torques $\tau_{c}$ when they lic within the attainable moment set or clsc approximates the commanded torques in a least-squares sense when they are not in the attainable moment set (the underlying quadratic programming problcm is infeasiblc).

\section{Autonomous Reconfigurable Control Allocation (ARCA)}

Reconfigurable control refers to the ability of a control allocation law to continuc to maintain tracking of the moment command $\tau_{c}$ in the face of actuator failures/degradation. In the short tcrm, actuator saturation is indistinguishable from actuator failure, since in both cascs an additional constraint is cntered into the control allocation law. However, in the casc of an actuator failure, the constraint is permancnt and thus requircs coordinated treatment between the control allocation law, the attitude control law, and the guidance law.

\subsection{Problem statement}

We formally describe the ARCA problem as follows. We shall denote the sequence of autopilot torque commands as $\tau_{c}(k)$ and the scquence of CA gencrated actuator command vectors as $\delta_{c}(k)$. In order to accomodate actuator ratc limits, we shall computc the actuator command vectors rocursivcly, i.c.,

$$
\delta_{c}(k)=\delta_{c}(k-1)+\delta_{e}(k)
$$

where $\delta_{e}(k)$ is an update to the previous actuator command vector $\delta_{c}(k-1)$. We shall omit the dependence on the time index $k$ where it is clear by context. We shall make use of the following definitions:

Definition 2.1 The actuator status vector $\delta_{\text {slal }}(t)$ has entrics in the range of $[0,1]$ wherc $\delta_{\text {slal }, i}=0$ reflects complete failure (actuator $i$ has no impact on vchiclc body torques) and $\delta_{s l a t, i}=1$ reflects nonminal opcration of actuator $i$.

Remark 2.1 We shall assume that the the actuator status vector $\delta_{\text {stal }}$ is made available to the CA modulc by, e.g., a vehiclc health monitoring system or an on-line system identification modulc. 
Definition 2.2 The cffective actuator Jacobian $\bar{G}(x)$ is the system Jacobian

$$
\bar{G}(x) \triangleq\left[\frac{\partial \tau_{b}}{\partial \delta}\right]
$$

cvaluated under current opcrating conditions, including effects of actuator degradation and failure.

Remark 2.2 Notice that the effective actuator Jacobian $\bar{G}(x)$ is unknown prior to flight timc. If the nominal systcm Jacobians $G(x) \approx F(x)^{\dagger}$ arc available, then $\bar{G}(x)=G(x) \operatorname{diag}\left(\delta_{\text {slal }}\right)$.

Definition 2.3 Given a sampling interval $T$, the current actuator position $\delta$ and vectors of actuator maximum position values $\delta^{+}$, minimum actuator position valucs $\delta^{-}$, and maximum actuator ratcs $\dot{\delta}_{\text {max }}$, the next-stcp feasible set $\Delta_{f}\left(\delta_{c}\right)$ is defined as

$$
\Delta_{f}\left(\delta_{c}\right) \triangleq\left\{\delta_{e}: \delta^{-} \leq \delta_{c}+\delta_{e} \leq \delta^{+} \text {and }\left|\delta_{e}-\delta\right| \leq T \dot{\delta}_{\max }\right\}
$$

Remark 2.3 The set $\Delta_{f}(\delta(k T))$ is the sct of legal next-step actuator commands $\delta_{c}((k+1) T)$ given current actuator position values $\delta(k)$.

Denoting $\delta_{c}=\delta_{c}(k-1), \delta_{e}(k)$, the reconfigurable control allocation problem can thus bc cxpressed as the quadratic programming problem [Luc84]

$$
\begin{aligned}
& \min \left(\delta_{c}+\delta_{e}\right)^{T} W_{1}\left(\delta_{c}+\delta_{e}\right)+\delta_{e}{ }^{T} W_{2} \delta_{e} \\
\text { subjcct to } & \bar{G}(x) \delta_{e}=\Delta \tau \\
\text { and } & \delta_{e} \in \Delta_{f}\left(\delta_{c}\right)
\end{aligned}
$$

where $W_{1}$ is a position penalty on the command vector $\delta_{c}(k), W_{2}$ is a ratc penalty on the change in command vector $\delta_{e}$, and $\Delta \tau$ is a torque command updatc, usually (but not always) defincd as $\Delta \tau(k)=\tau_{c}(k)-\tau_{c}(k-1)$. Exccptions to this rulc arc discussed bclow.

In the case where the quadratic programming problem (2.1) is feasible, then the minimization scarches for an update $\delta_{e}$ that matches the commanded torque while roducing the magnitude (cost) of the control command. Converscly, if the idcal torque command is not feasible, i.c., no solution $\delta_{e} \in \Delta_{f}\left(\delta_{c}\right)$ cxists to the equality constraint $\bar{G}(x) \delta_{e}=\Delta \tau$, then it is necessary to relax the cquality constraint and instcad find a vertex (cxtreme point [Luc84]) of the feasible set $\Delta_{f}\left(\Delta_{c}\right)$ that minimizes the norm $\left\|\tau_{e r r}(k)\right\|$ where $\tau_{e} \triangleq \bar{G}(x) \delta_{e}-\Delta \tau$. In this casc, the next valuc of $\Delta \tau$ is sclected to reflect both the update to the torque command $\tau_{c}$ and the "unallocatcd" torque $\tau_{e}$ from the previous itcration.

Brutc force application of standard quadratic programming techniques may not be desirable in the ARCA problem for the following reasons.

1. Computation timc: solution of the quadratic programming problem can requircs scveral itcrations, cach requiring solution of a lincar systcm of cquations $A x=b$ of dimcnsion up to $n_{a} \times n_{a}$.

2. Repetition: the quadratic programming problem to be solved in our application is solved repcatedly for problems and conditions that do not vary grcatly from onc sample time to the ncxt. For cxamplc, during times of highly aggressive mancuvers, it is likely that the same actuators are saturated from one time stcp to the next. The similarity of these problems is not exploited by standard quadratic programming techniques.

Dept. Elcct. \& Comp. Eng., Auburn Univ.

A. S. Hodcl \& R. Callahan 
3. Singular dual solution: because the number of constraints is always 4 times the number of unknowns, the dual problem [Luc69] used to solve for the corresponding Lagrange multiplicr in a non-negative least squares problcm is singular, which requircs at the lcast an incrcase in the dimension of the problem solution via the usc of "slack" variables.

\subsection{Fast QP solution to ARCA}

Given the concerns raiscd above, we propose the usc of a fast QP solution method that differs from standard primal problem QP solvers in two ways:

1. The solution (active constraint set [Luc84]) of the previous problem is used as a starting point of the current problem.

2. The number of QP itcrations is limited so that computational burden is reduced.

We consider here the equivalent QP problem using the notation of [Luc84].

$$
\begin{array}{ll} 
& \min _{x} J(x) \triangleq x^{T} Q x+c^{T} x \\
\text { subject to } & A x=b \\
& x^{-} \leq x \leq x^{+}
\end{array}
$$

The unknowns $x$ in problem (2.2) corrcspond to the actuator command deviations $\delta_{e}$ in the ARCA algorithm description. We shall procced on the following assumptions:

1. $x^{-} \leq 0 \leq x^{+}$; i.c., the previous actuator command vector satisfics actuator constraint limits.

This assumption may be violated in the casc of, c.g., initial transicnts duc to cngine failure, where additional constraints on differential thrust can be imposed upon failure. Neverthelcss, the above assumption will be reasonable in all cascs where additional constraints are not suddenly imposed on actuator command bchavior.

2. The torque command issucd by the autocommander is feasible. This condition is can be met through the use of on-line computation of a local attainable moment set [?].

Based on the above assumptions, we may solve the QP problem (2.2) as illustrated in Figurc 2. The initial point $x(0)$ by assumption satisfics the incquality constraints $x^{-} \leq x(0) \leq x^{+}$, but may not satisfy the equality constraint $A x=b$ duc to variations in the (cffective) Jacobian and torque command from one time step to the next. The point $w(0)$ is computed that minimizes the optimization

$$
\begin{aligned}
\min _{w(0)} & w(0)^{T} Q w(0)+c^{T} w(0) \\
\text { subjcct to } & \bar{A} w(0)=\bar{b}
\end{aligned}
$$

with $\bar{A}=A, \bar{b}=b$. As illustratcd in the figurc, $w(0)$ will satisfy the cquality constraints, but may not satisfy the incquality constraints. We therefore choose our next solution value $x(1)=(1-$ $\alpha) x(0)+\alpha w(0)$ where $w(0)$ is chosen so that $x(1)$ lics at the cdge of the feasible set for the incquality constraints. We then append a row to $\bar{A}$ and $\bar{b}$ corresponding to the new "active constraint," $x_{1}=x_{1}^{-}$in the case of the figurc, and solve the minimization (2.3) again, now constrained to the intersection of the hyperplancs $A x=b$ and $x_{1}=x_{1}^{-}$. This process continucs until the itcrate $w(k)$ is in the feasible set of problem (2.2). (Such a solution cxists by assumption.) 


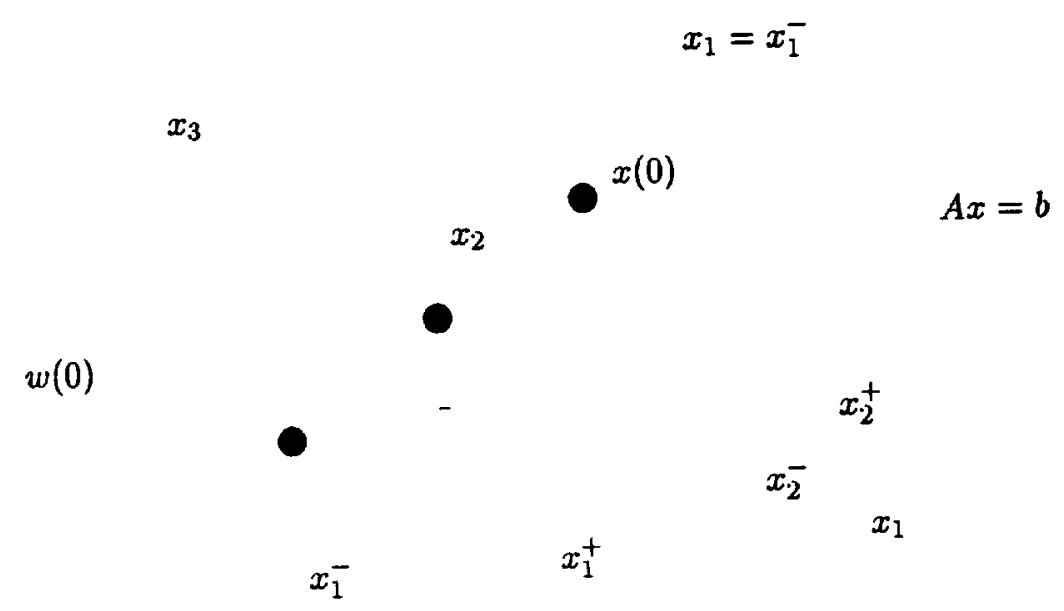

Figurc 2: Quadratic programming problem (2.2) solution method for the ARCA problem. The feasible solution set is denoted by the rectanglc on the interior of the hypcrplanc $A x=b$.

Remark 2.4 Bccause the system Jacobians are continuous (except in the casc of sudden failure), the active constraints from onc itcration to the next will likcly not change often. As a result, the above algorithm may be casily modificd to solve the minimization (2.3) at most once per control step while cvaluating revisions to the active constraint set by projecting the gradicnt

$$
\frac{\partial J}{\partial x}=2 Q x+c
$$

onto the null space of $A$

$$
v=\left(I-A^{\dagger} A\right)(2 Q x+c)
$$

and comparing the signs of the resulting gradicnt scarch direction $v$ with the active constraints imposed on $x$ from the previous itcration.

\section{Conclusions}

Our initial tests of our fast QP solution method on artificially gencrated problems are very cncouraging. For the final version of this paper we shall present closed-loop results using the ARCA algorithm in closed loop with a high-fidelity model of the X-33 cxpcrimental launch vehicle.

Dept. Elcct. \& Comp. Eng., Auburn Univ. 6

A. S. Hodel \& R. Callahan 


\section{References}

[BD95] Kenneth A. Bordignon and Waync C. Durham. Closod-form solutions to constraincd control allocation problcm. Journal of Guidance, Control, and Dynamics, 18(5):10001007, Scptcmber-October 1995.

[BEFB94] Stcphen Boyd, Laurcnt El Ghaoui, Eric Fcron, and Venkataramanan Balakrishnan. Lincar Matrix Incqualitics in System and Control Thcory. SIAM, 1994.

[BLM99] Jovan D. Boskovic, Sai-Ming Li, and Raman K. Mchra. Globally stable adaptive tracking control design for spacceraft under input saturation. In Conference on Decision and Control, pagcs 1952-1957, Deccmber 1999.

[BP98] Marc Bodson and William A. Pohlchuck. Command limiting in reconfigurable flight control. Journal of Guidance, Control, and Dynamics, 21(4), 1998.

[Buf97] James M. Buffington. Tailless aircraft control allocation. In Procecdings of the 1997 AIAA Guidance, Navigation, and Control Conference, pagcs 737-747. AIAA, 1997.

[CBP98] P. Chandler, J. Buffington, and M. Pachtcr. Integration of on-line systcm identification and optimization-based control allocation. 1998 AIAA Guidance, Navigation, and Control Conference, 1998.

[CG86] H. F. Chen and L. Guo. Convergence rate of least squares identification and adaptive control for stochastic systems. Intcrnational J. of Control, 44:1459-1476, 1986.

[CGD ${ }^{+98] ~ F . ~ Z . ~ C h a o u i, ~ F . ~ G i r i, ~ L . ~ D u g a r d, ~ J . ~ M . ~ D i o n, ~ a n d ~ M . ~ M ' s a a d . ~ A d a p t i v c ~ t r a c k i n g ~}$ with saturating input and controller integral action. IEEE Transactions on Automatic Control, 43(11):1368-1643, November 1998.

[CPM95] P. R. Chandler, M. Pachter, and M. Mcars. System identification for adaptive and reconfigurable control. Journal of Guidance, Control, and Dynamics, 18(3):516-524, May-Junc 1995.

[Dur93] Waync C. Durham. Constraincd control allocation. Journal of Guidance, Control, and Dynamics, 16(4):717-725, August 1993.

[Enn98] D. F. Enns. Control allocation approaches. In Proccedings of the AIAA Guidance, Navigation, and Control Conference, Boston, 1998. Papcr No. 98-4108.

[HC02] A. S. Hodcl and R. Callahan. Dynamic control allocation for reusable launch vehiclcs. Submittcd to 2002 Southcastcrn Symposium on Systcm Thcory, Hunstville AL, March 2002.

[HJN91] A. J. Helmicki, C. A. Jacobson, and C. N. Nett. Control oriented system identification: A worst casc/detcrministic approach in (o. IEEE Transactions on Automatic Control, 36(10):1163-1176, Octobcr 1991.

[HSZ01] A. Scottcdward Hodel, Yuri Shtcsscl, and J. Jim Zhu. Robust inversion and data compression in control allocation for rcusable launch vchicles. J. Guidance, Control, and Dynamics, 2001. submitted for publication.
Dept. Elect. \& Comp. Eng., Auburn Univ.
7
A. S. Hodel \& R. Callahan 
[Luc69] D. G. Lucnbergcr. Optimization by Vector Space Mcthods. Wilcy and Sons, Inc., Ncw York, NY, 1969.

[Luc84] D. G. Lucnbcrger. Introduction to Lincar and Nonlincar Programming. Addison-Wcslcy, Reading, MA, 2nd cdition, 1984.

[PB00] John A. M. Petcrsen and Marc Bodson. Control allocation for systcms with coplanar controls. AIAA Guidancc, Navigation, and Control Conference and Exhibit, A0037182:1-11, August 2000.

[SHJ00] Y. Shtcsscl, C. E. Hall, and M. Jackson. Rcusable launch vchicle control in multiplc time scalc sliding modes. In Procecdings of AIAA Guidance, Navigation, and Control Conference, number AIAA-2000-4155, Denver, Co, August 14-17 2000. AIAA.

$\left[\mathrm{SMJ}^{+98]}\right.$ Y. Shtcsscl, J. McDuffic, M. Jackson, C. Hall, D. Krupp, M. Gallaher, and N. Hentrix. Sliding mode control of the $\mathrm{x} 33$ vehicle in launch and re-cntry modes. In Procecdings of AIAA Guidance, Navigation, and Control Conference, number 98-4414, pagcs 13521362, Boston, MA, August 10-12 1998. AIAA.

Dcpt. Elcct. \& Comp. Eng., Auburn Univ. 8

A. S. Hodel \& R. Callahan 